\title{
Cinética de secagem de grãos de arroz-vermelho
}

\author{
Drying kinetics of red rice grains
}

Dyego da Costa Santos ${ }^{[a]}$, Emanuel Neto Alves de Oliveirad ${ }^{[a]}$

[a] Tecnólogo em Alimentos, doutorando em Engenharia Agrícola, Universidade Federal de Campina Grande (UFCG),

Campina Grande, PB - Brasil, e-mail: dyego.csantos@gmail.com; emanuelnetoliveira@ig.com.br

\section{Resumo}

A secagem de produtos agrícolas é o processo mais utilizado para assegurar sua qualidade e estabilidade, levando-se em consideração que a diminuição da quantidade de água do material reduz a atividade biológica, bem como as mudanças químicas e físicas que ocorrem durante o armazenamento. Por isso, o presente trabalho foi desenvolvido com o objetivo de estudar a secagem de grãos de arroz-vermelho (Oryza sativa L.) em secador de leito fixo nas temperaturas de 30, 40 e $50 \stackrel{\circ}{\circ} \mathrm{C}$ e ajustar diferentes modelos matemáticos aos dados experimentais. Como critério de avaliação destes, utilizou-se o coeficiente de determinação $\left(R^{2}\right)$ e o desvio quadrático médio (DQM). Observou-se que incrementos no valor da temperatura do ar de secagem promoveram redução significativa no tempo de secagem. Entre os modelos ajustados, os de Aproximação da Difusão e Dois Termos apresentaram os maiores valores de $\mathrm{R}^{2}$ e os menores valores de DQM para a faixa de temperatura de $30 \stackrel{\circ}{\circ}$ a $50 \stackrel{\circ}{ } \mathrm{C}$.

Palavras-chave: Oryza sativa L. Desidratação. Modelos matemáticos.

\section{Abstract}

This study aimed to evaluate the variability of physicochemical components, inter and intraplant, of seeds of two cotton cultivars (BRS-272 and BRS-273) harvested at three vertical positions of the plant (base; middle and pointer) and two horizontal positions (1st and 2nd fruiting positions). Seeds were subjected to physical and chemical analysis. The lower moisture content was found in the seeds of the cultivar BRS-272 of the 1 st fruit of middle vertical position of the plant. It was observed a variation of $18.42 \%$ to $25.00 \%$ in lipid content and $27.39 \%$ to $31.98 \%$ for proteins. The highest values of carbohydrates were found in the seeds of BRS-273 of 
the second fruit of the vertical pointer, while the values for the ashes were establish at the base of cultivars. The seeds of 1st and 2nd fruit from the vertical pointer position (variety BRS-272) were the samples which showed the highest levels of phosphorus. The highest levels of iron were found in the seeds of BRS-273 of the first fruit and second fruit of the middle vertical position of the plant, and potassium levels were originated in the same cultivar, in the seeds of the first and second fruit of the base. In relation to lipid content, the highest percentages were located at the base of the plant. It is concluded that there is inter and intraplant phenotypic variation for the genotypes studied.

Keywords: Gossypium hirsutum. Position. Fruit. Nutritional composition. Minerals.

\section{Introdução}

O arroz apresenta grande diversidade genética, com milhares de variedades cultivadas no mundo, entre as quais estão as que a coloração do pericarpo do grão é avermelhada (chamado de arroz-vermelho). 0 arroz-vermelho tradicional, pertencente à mesma espécie do arroz cultivado (Oryza sati$v a$ L.), apresenta porte alto, folhas verde claras, decumbentes e pilosas, colmos finos, alta capacidade de afilhamento e sementes com pericarpo avermelhado, aristas longas, altas taxas de dormência e debulha natural (KWON; SMITH JR.; TALBERT, 1992).

De acordo com Pereira e Ramos (2004), no Brasil, o arroz-vermelho é cultivado principalmente no Nordeste, destacando-se, por ordem decrescente de produção, os estados da Paraíba, Rio Grande do Norte, Pernambuco, Ceará e Bahia, sendo também encontrado em alguns municípios do norte de Minas Gerais. Em todas essas áreas, sua produção está relacionada com o hábito alimentar das populações locais, mas, apesar de sua grande importância, esse tipo de arroz se encontra em franco processo de extinção, devido à forte concorrência da indústria do arroz branco e ao despovoamento do meio rural. Estima-se que a sua área atualmente plantada esteja reduzida a um terço do que já foi no passado. Na maioria dos estados nordestinos, o arroz-vermelho é um alimento especial nas casas das famílias e nos restaurantes do interior. os

Sogi et al. (2003) relatam que a secagem é uma técnica largamente usada na preservação de alimentos. É uma operação de transferência simultânea de calor e massa, em que a água é removida do alimento e carreada pelo ar quente. Segundo Afonso
Júnior e Corrêa (1999), a remoção de água excessiva contida no interior do grão ocorre por meio de evaporação, geralmente causada por convecção forçada de ar aquecido, de modo a permitir a manutenção de sua qualidade durante o armazenamento por longos períodos de tempo.

Para Christensen e Kaufmann (1974), a conservação pela secagem se baseia no fato de que tanto os microrganismos como as enzimas e todo o mecanismo metabólico necessitam de certa quantidade de água para suas atividades. Com a redução da água disponível, consequentemente serão reduzidas a atividade de água e a velocidade das reações químicas no produto, bem como o desenvolvimento de microrganismos.

De acordo com Leite et al. (2005), a utilização de modelos matemáticos na secagem de produtos agrícolas é de fundamental importância, pois com tais modelos torna-se possível a simulação matemática da operação de secagem e, portanto, o estudo do comportamento das variáveis relacionadas ao processo.

Várias pesquisas têm sido desenvolvidas com o objetivo de estudar a cinética de secagem de diversos produtos agrícolas: fatias de alho (MADAMBA; DRISCOLL; BUCKLE, 1996); sementes de feijão (AFONSO JÚNIOR; CORRÊA, 1999; CORRÊA et al., 2007; RESENDE; FERREIRA; ALMEIDA, 2010); grãos de milho de pipoca (CORRÊA; MACHADO; ANDRADE, 2001); milho (LEITE et al., 2005); farelo de mamona (SOUSA et al., 2006); polpa de facheiro (LIMA; FIGUEIRÊDO; QUEIROZ, 2007); folhas de capim-limão (MARTINAZZO et al., 2007); polpa de tamarindo (SILVA et al., 2008); cana-de-açúcar (GOYALDE et al., 2009); café (RESENDE et al., 2009; RESENDE et al., 2010); banana-maçã (SILVA et al., 
2009); seriguela (FURTADO et al., 2010). No entanto, são escassas as informações sobre a secagem de grãos de arroz-vermelho.

Assim, o objetivo do trabalho foi estudar a secagem de grãos de arroz-vermelho (Oryza sativa L.) em secador de leito fixo nas temperaturas de 30, 40 e $50{ }^{\circ} \mathrm{C}$ e ajustar diferentes modelos matemáticos aos dados experimentais.

\section{Materiais e métodos}

O estudo foi conduzido no Laboratório de Armazenamento e Processamento de Produtos Agrícolas (LAPPA) da Universidade Federal de Campina Grande, em Campina Grande (PB). Utilizou-se como matéria-prima grãos de arroz-vermelho (Oryza sativa L.) adquiridos no mercado varejista da cidade de Campina Grande.

Inicialmente, foi determinado o teor de água inicial (11\% b.u.) dos grãos de arroz-vermelho pelo método padrão em estufa a $105 \pm 3{ }^{\circ} \mathrm{C}$ por $24 \mathrm{~h}$, com três repetições, sendo posteriormente processado o umedecimento dos grãos até $28 \%$ b.u. para o realização das secagens.

As amostras foram secas em camada fina (aproximadamente $40 \mathrm{~g}$ ), em secador de leito fixo, nas temperaturas de 30,40 e $50{ }^{\circ} \mathrm{C}$ e velocidade do ar de secagem de aproximadamente $1,4 \mathrm{~m} \mathrm{~s}^{-1}$.

0 fluxo de ar foi determinado a partir da velocidade do ar de secagem, utilizando-se um anemômetro de lâminas rotativas. Também foram verificadas a umidade relativa e a temperatura do ambiente durante a realização dos experimentos, por meio de higrômetro.

Os experimentos foram realizados em quadruplicata, e durante a operação de secagem as leituras em relação à perda de peso das amostras foram efetuadas em intervalos regulares de $5,10,15$ e 30 min. A perda de peso foi acompanhada até o peso constante. Em seguida, foi determinada a matéria seca dos grãos de arroz-vermelho pelo método padrão em estufa a $105 \pm 3{ }^{\circ} \mathrm{C}$ por $24 \mathrm{~h}$. Os dados experimentais foram expressos na forma de razão de água (RX):

$$
R X=\frac{X-X_{e}}{X_{i}-X_{e}}
$$

sendo:

RX: razão de água do produto (adimensional);

$\mathrm{X}$ : teor de água do produto;

$\mathrm{X}_{\mathrm{i}}$ :teor de água inicial do produto; $\mathrm{e}$

$\mathrm{X}_{\mathrm{e}}$ :teor de água de equilíbrio do produto.

As razões de água e as curvas de razão de água em função do tempo de secagem foram calculadas e construídas a partir dos dados de perda de massa das amostras durante as secagens e dos teores de água de equilíbrio determinadas ao final delas. No cálculo da razão de água foi utilizada a equação 1 .

Os modelos matemáticos de Aproximação da Difusão, Exponencial Dois Termos, Henderson e Pabis, Logarítmico, Midilli, Newton, Page e Page Modificada (Quadro 1) foram ajustados às curvas experimentais de secagem utilizando-se o programa computacional STATISTICA 5.0 por meio da análise de regressão não linear, pelo método QuaseNewton. Para se determinar o melhor ajuste de cada equação aos dados experimentais foram utilizados os coeficientes de determinação $\left(\mathrm{R}^{2}\right)$ e o desvio quadrático médio (DQM):

$$
\mathrm{DQM}=\left[\frac{1}{\mathrm{n}} \sum_{\mathrm{i}=1}^{\mathrm{n}}\left(\mathrm{RX}_{\mathrm{pred}, \mathrm{i}}-\mathrm{RX}_{\mathrm{exp}, \mathrm{i}}\right)^{2}\right]^{\frac{1}{2}}
$$

sendo:

DQM: desvio quadrático médio;

$\mathrm{RX}_{\text {pred: }}$ razão de água predito pelo modelo;

$\mathrm{RX}_{\text {exp }}$ : razão de água experimental;

n: número de observações.

Quadro 1 - Modelos matemáticos de regressão não linear, avaliados para predizer a secagem do arroz-vermelho

\begin{tabular}{llr}
\hline Designação do Modelo & Modelo & \\
\hline$R X=a \cdot \exp (-k . t)+(1-a) \cdot \exp (-k . b . t)$ & Aproximação da Difusão & $(3)$ \\
$R X=a \cdot \exp (-k . t)+(1-a) \cdot \exp (-k . a . t)$ & Exponencial Dois Termos & $(4)$ \\
$R X=a \cdot \exp (-k . t)$ & Henderson e Pabis & $(5)$ \\
$R X=a \cdot \exp (-k . t)+b . \exp (-q . t)$ & Dois Termos & $(6)$ \\
$R X=a \cdot \exp \left(-k . t^{n}\right)+b . t$ & Midilli & $(7)$ \\
$R X=\exp \left(-k . t^{2}\right)$ & Newton & $(8)$ \\
$R X=\exp \left(-k . t^{n}\right)$ & Page & $(9)$ \\
$R X=\exp (-k . t) \cdot n$ & Page Modificada \\
\hline
\end{tabular}

Legenda: RX: razão de água (adimensional); t: tempo (min); a, b, q, k, n: constantes do modelo.

Fonte: Dados da pesquisa. 


\section{Resultados e discussão}

Na Tabela 1 estão apresentados os valores dos coeficientes de determinação $\left(\mathrm{R}^{2}\right)$ e desvios quadráticos médios (DQM) para cada um dos modelos matemáticos ajustados aos dados experimentais da cinética de secagem de grãos de arroz-vermelho.

Conforme os resultados obtidos para os coeficientes de determinação ajustados $\left(\mathrm{R}^{2}\right)$ e os desvios quadráticos médios (DQM), todos os modelos matemáticos avaliados apresentaram ajuste adequado para descrever o processo de secagem do arroz-vermelho nas temperaturas de 30,40 e $50{ }^{\circ} \mathrm{C}$. Observase que o DQM variou entre 0,0009 e 0,0723 , sendo que os modelos de Aproximação da Difusão e Dois Termos revelaram os menores valores de DQM. De acordo com Silva et al. (2009), quanto menor o valor do DQM melhor é a representação do modelo empregado. Lima et al. (2007), no estudo da secagem da polpa de facheiro, analisaram o comportamento dos modelos semiteóricos de Page e Midilli e encontraram valores de DQM baixos, o que significa que estes modelos se ajustaram bem aos dados experimentais. Silva et al. (2008), pesquisando a desidratação da polpa de tamarindo, verificaram que os modelos de Midilli, seguidos dos modelos de Page e Henderson e Pabis, apresentaram os menores valores de DQM. Em relação ao coeficiente de determinação $\left(\mathrm{R}^{2}\right)$, ambos os modelos apresentaram valores elevados, acima de 0,99, com exceção das equações de Henderson e Pabis, Newton e Page Modificada, que apresentaram valores de $\mathrm{R}^{2}$ superiores a 0,98. Entre todos os modelos empregados, os de Aproximação da Difusão e Dois Termos apresentaram os maiores valores de $\mathrm{R}^{2}$. Madamba, Driscoll e Buckle (1996) estudaram a secagem de alho em camada fina e relataram que o coeficiente de determinação elevado significa um bom ajuste para representação do fenômeno de secagem. Esses resultados indicam que todos os modelos matemáticos ajustados podem ser utilizados na predição da cinética de secagem de grãos de arroz-vermelho.

Resende et al. (2009), estudando a modelagem matemática para a secagem de clones de café (Coffea canephora Pierre) em terreiro de concreto, verificaram que os modelos de Aproximação da Difusão e Dois Termos foram satisfatórios para a descrição do fenômeno para o clone Cpafro 180. Martinazzo et al. (2007), analisando e descrevendo matematicamente a cinética de secagem de folhas de capim-limão, concluíram que o modelo matemático em camada fina, proposto por Midilli foi o que melhor se ajustou aos dados experimentais. Resende et al. (2010) investigaram a cinética de secagem de clones de

Tabela 1 - Valores dos coeficientes de determinação ajustados $\left(R^{2}\right)$ e dos desvios quadráticos médios (DQM), para os modelos matemáticos avaliados

\begin{tabular}{llllllll}
\hline Modelo Matemático & Temp. $\left({ }^{\circ} \mathbf{C}\right)$ & $\mathbf{R}^{2}$ & DQM & Modelo Matemático & Temp. $\left({ }^{\circ} \mathbf{C}\right)$ & $\mathbf{R}^{2}$ & DQM \\
\hline \multirow{2}{*}{ Aproximação da Difusão } & 30 & 0,9994 & 0,0036 & & 30 & 0,9992 & 0,0052 \\
& 40 & 0,9992 & 0,0052 & Midilli & 40 & 0,9987 & 0,0066 \\
& 50 & 0,9997 & 0,0009 & & 50 & 0,9977 & 0,0091 \\
Exponencial Dois Termos & 30 & 0,9974 & 0,0335 & & 30 & 0,9874 & 0,0545 \\
& 40 & 0,9946 & 0,0462 & Newton & 40 & 0,9825 & 0,0687 \\
Henderson e Pabis & 50 & 0,9982 & 0,0216 & & 50 & 0,9944 & 0,0412 \\
& 30 & 0,9907 & 0,0604 & & 30 & 0,9987 & 0,0225 \\
Dois Termos & 40 & 0,9855 & 0,0723 & Page & 40 & 0,9980 & 0,0252 \\
& 50 & 0,9947 & 0,0431 & & 50 & 0,9974 & 0,0225 \\
& 30 & 0,9995 & 0,0049 & & 30 & 0,9907 & 0,0604 \\
& 40 & 0,9993 & 0,0061 & Page Modificada & 40 & 0,9855 & 0,0723 \\
\hline
\end{tabular}

Fonte: Dados da pesquisa. 
café (Coffea canephora Pierre) em terreiro de chão batido e concluíram que os modelos Verma, Dois Termos e Aproximação da Difusão foram adequados para a representação da secagem dos quatro clones de café analisados. Corrêa, Machado e Andrade (2001), ao pesquisarem a cinética de secagem e qualidade de grãos de milho de pipoca, constataram que o modelo de secagem em camada fina, proposto por Page, se ajustou satisfatoriamente às curvas de secagem obtidas experimentalmente para o milho de pipoca da cultivar Zélia. Corrêa et al. (2007), estudando a modelagem matemática para a descrição do processo de secagem do feijão (Phaseolus vulgaris L.) em camadas delgadas, concluíram que os modelos Midilli, Dois termos e Aproximação da difusão representam bem o fenômeno de secagem do feijão. Goyalde et al. (2009) pesquisaram a modelagem matemática da cinética de secagem da cana-de-açúcar cultivada e verificaram que o modelo de Midilli foi o que melhor se ajustou aos dados de secagem da cana-de-açúcar picada. Resende, Ferreira e Almeida (2010), na pesquisa da modelagem matemática para a descrição da cinética de secagem do feijão adzuki (Vigna angularis), concluíram que, entre os modelos analisados, Midilli e Henderson e Pabis Modificado apresentaram os melhores ajustes para a descrição da cinética de secagem do feijão adzuki. Furtado et al. (2010) estudaram a secagem de polpa de seriguela pelo método de camada de espuma e verificaram que os modelos matemáticos de Midilli e Kucuk foram os que melhor descreveram o comportamento da secagem.

Observam-se, nos Gráficos 1 e 2, as curvas de secagem para as temperaturas de 30,40 e $50{ }^{\circ} \mathrm{C}$, juntamente com os valores ajustados pelos modelos matemáticos avaliados. 0 tempo de secagem decresceu com o aumento da temperatura do ar, quando os tempos médios necessários para completar o processo de secagem foram de 360, 270 e 225 minutos para as temperaturas de 30,40 e $50{ }^{\circ} \mathrm{C}$, respectivamente. Constatou-se ainda que os valores de teor de água de equilíbrio calculados após a secagem foram de: 9,$09 ; 6,12$ e 4,65\% b.u., respectivamente, para a secagem com ar aquecido a 30,40 e $50^{\circ} \mathrm{C}$.
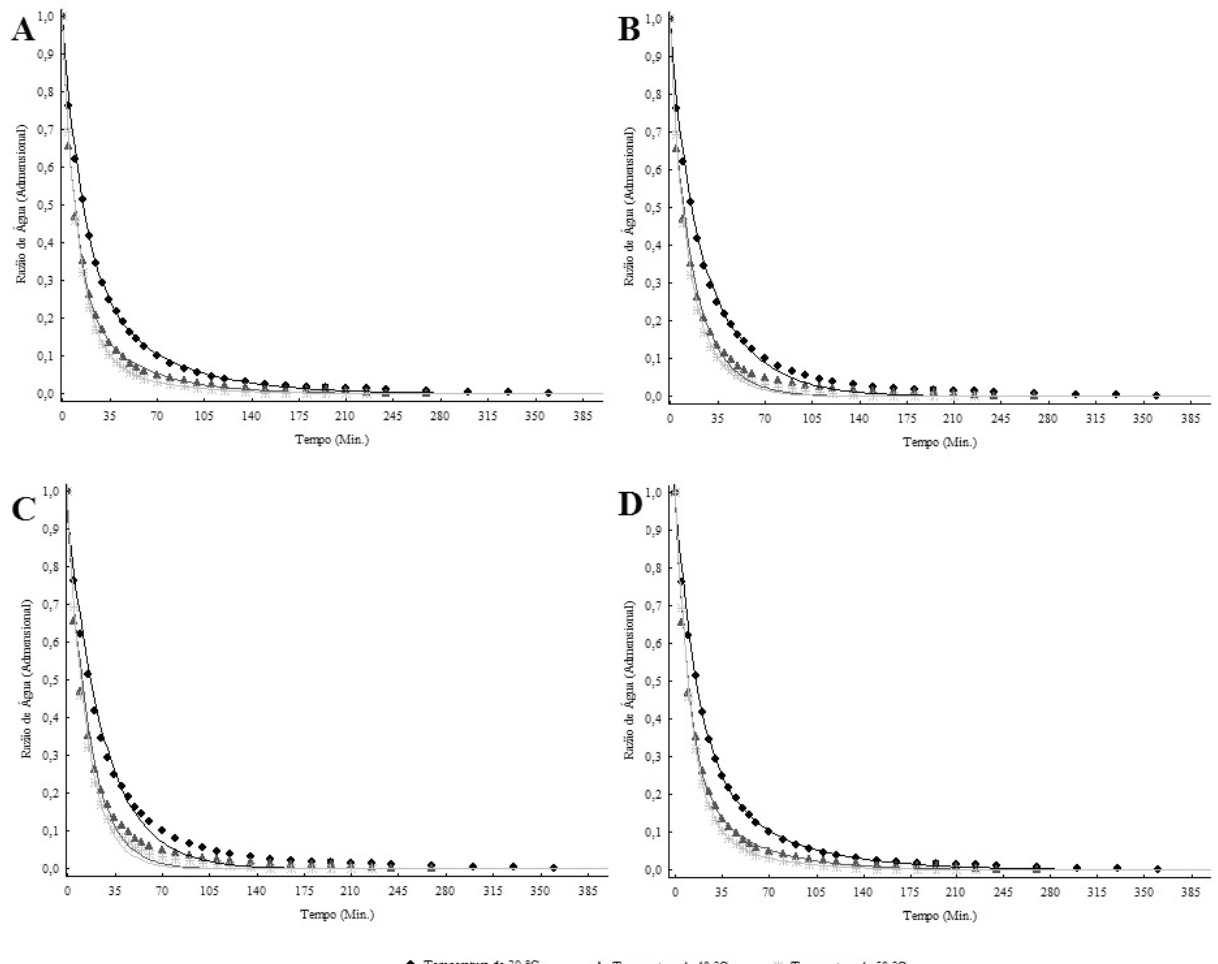

Gráfico 1 - Curvas de secagem determinadas nas temperaturas de 30,40 e $50{ }^{\circ} \mathrm{C}$ através dos modelos matemáticos Legenda: Aproximação da Difusão (A); Exponencial Dois Termos (B); Henderson e Pabis (C) e Dois Termos (D).

Fonte: Dados da pesquisa. 

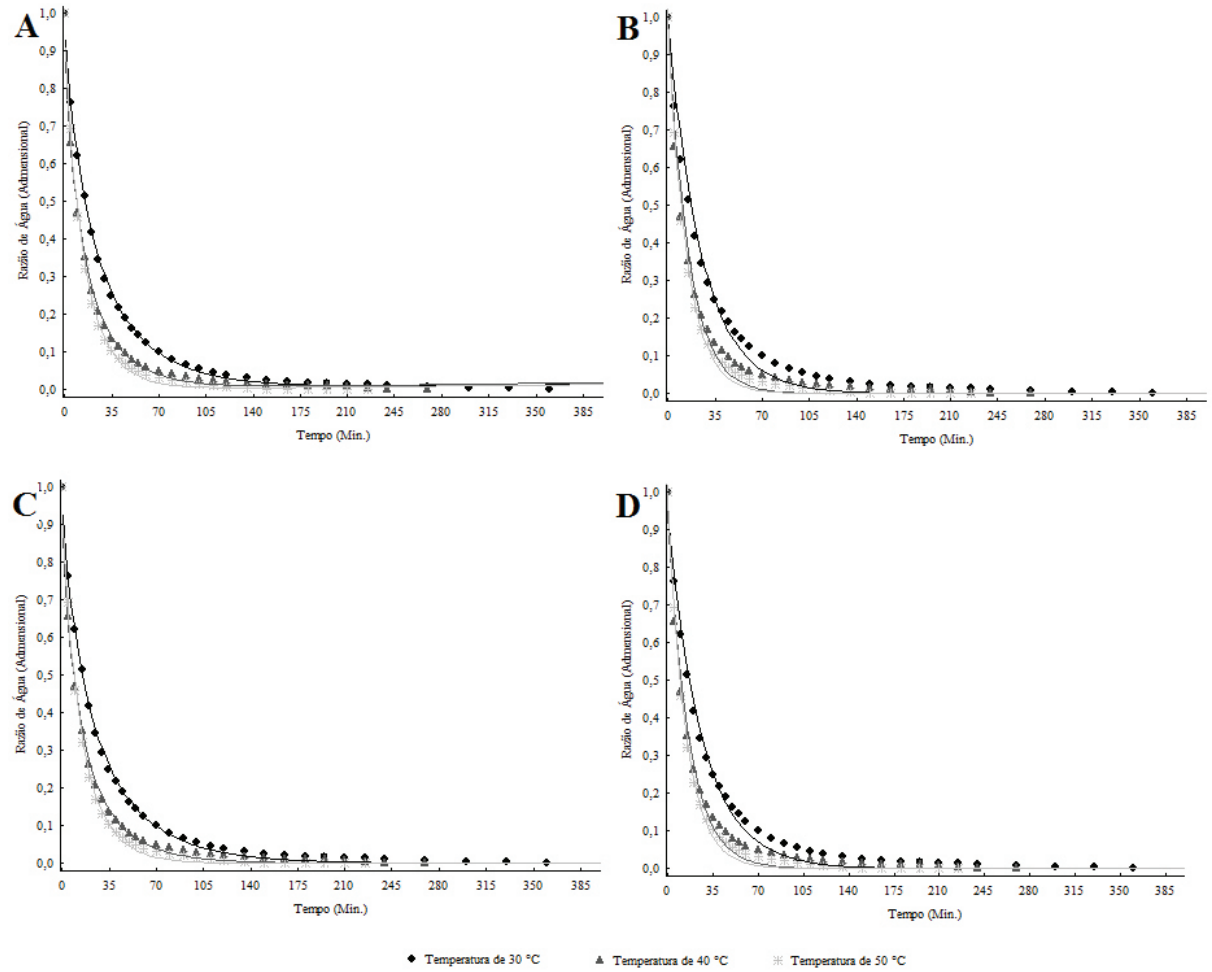

Gráfico 2 - Curvas de secagem determinadas nas temperaturas de 30,40 e $50^{\circ} \mathrm{C}$ por meio dos modelos matemáticos Legenda: Midilli (A); Newton (B); Page (C) e Page Modificada (D).

Fonte: Dados da pesquisa.
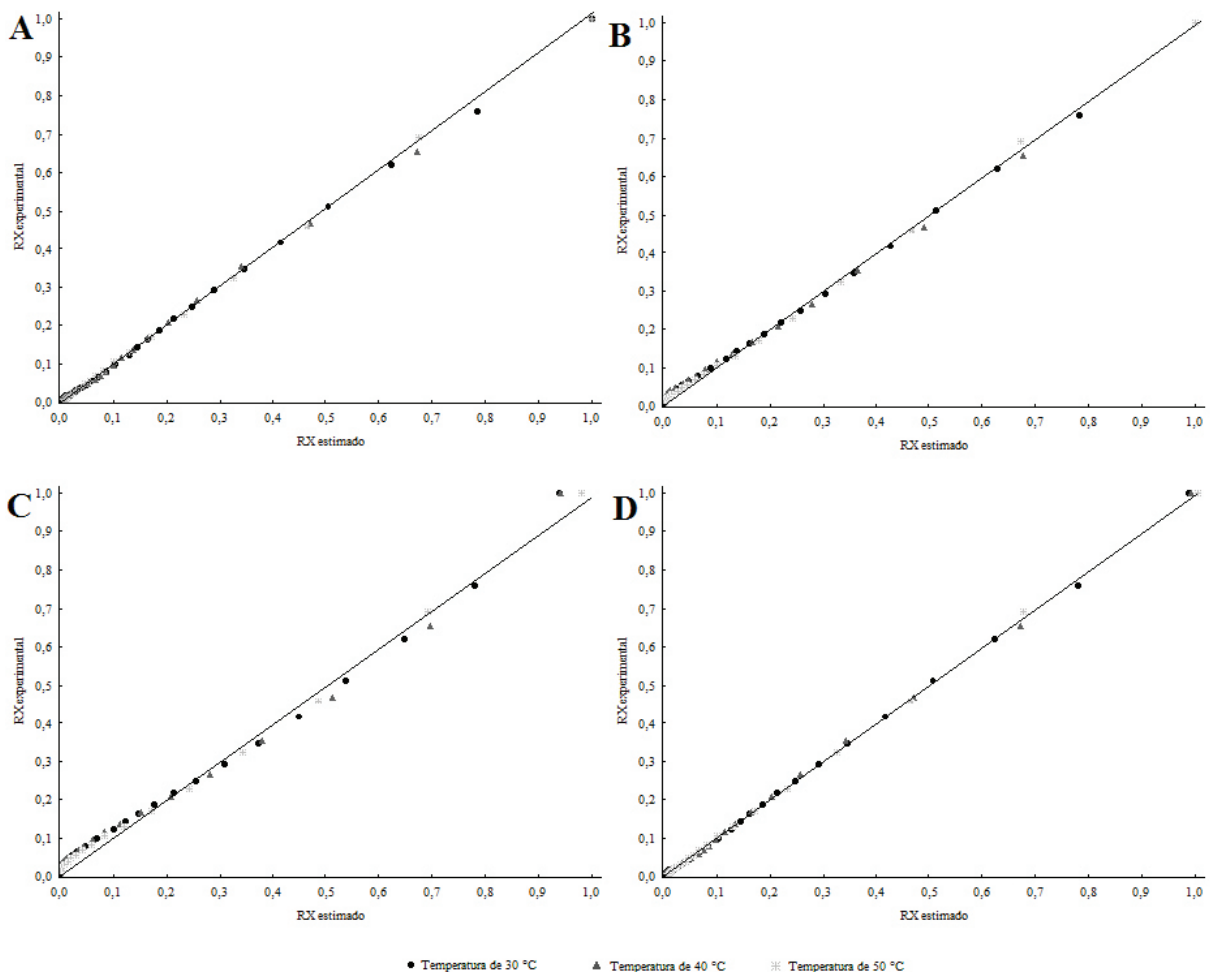

Gráfico 3 - Relação entre os valores experimentais e estimados da razão de água através dos modelos matemáticos Legenda: Aproximação da Difusão (A); Exponencial Dois Termos (B); Henderson e Pabis (C) e Dois Termos (D). Fonte: Dados da pesquisa. 

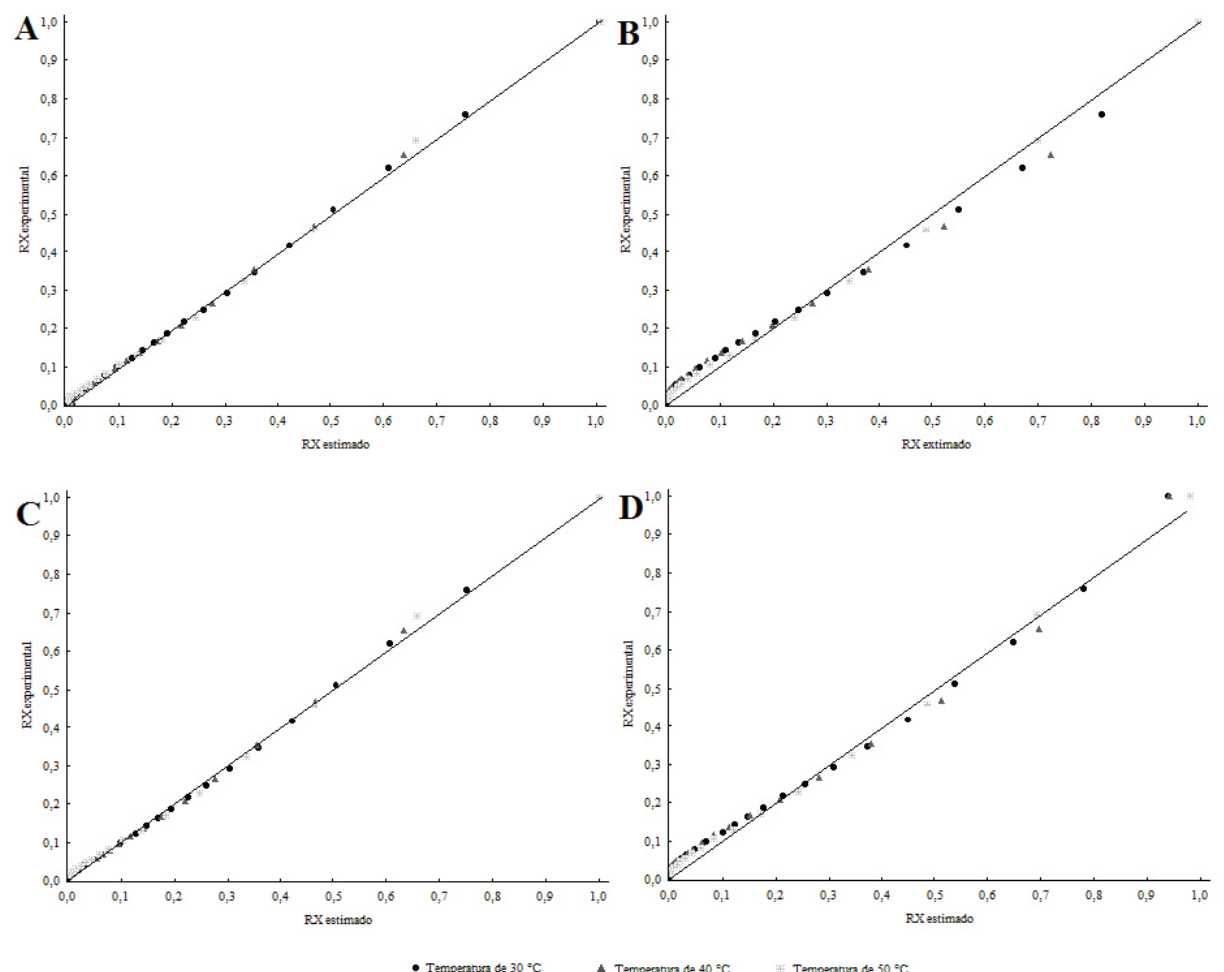

Gráfico 4 - Relação entre os valores experimentais e estimados da razão de água por meio dos modelos matemáticos Legenda: Midilli (A); Newton (B); Page (C) e Page Modificada (D).

Fonte: Dados da pesquisa.

Nos Gráficos 3 e 4 estão apresentados os dados de razão de água ( $\mathrm{RX})$, experimentais e estimados, obtidos a partir dos modelos matemáticos estudados para a secagem de grãos de arroz-vermelho nas temperaturas de 30,40 e $50{ }^{\circ} \mathrm{C}$. Afonso Júnior e Corrêa (1999) relatam que esse tipo de gráfico indica o ajuste das equações de secagem, ou seja, a dispersão dos dados experimentais em relação aos dados estimados, considerando-se todos os dados obtidos durante o experimento. Constata-se que todos os modelos matemáticos apresentaram os dados experimentais próximos à reta que passa pela origem, o que teoricamente representa a igualdade entre os valores experimentais e estimados e indica bom ajuste dos modelos utilizados.

Na Tabela 2, encontram-se os valores estimados dos parâmetros dos modelos matemáticos de Aproximação da Difusão, Midilli, Henderson e Pabis, Dois Termos, Page, Page Modificada, Newton e Exponencial Dois Termos, ajustados aos dados experimentais das cinéticas de secagem de grãos de arroz-vermelho nas temperaturas de 30, 40 e 50 ${ }^{\circ} \mathrm{C}$.

De acordo com Resende et al. (2010), a seleção e recomendação do melhor modelo se fundamentam na simplicidade e no número de coeficientes. Observa-se que para os modelos de Aproximação da Difusão, Exponencial Dois Termos, Dois Termos, Midilli e Page não houve comportamento padrão dos parâmetros (em pelo menos um destes) dos modelos com o aumento da temperatura. Lima et al. (2007) também observaram comportamento semelhante ao trabalharem com polpa de facheiro. Para os modelos de Henderson e Pabis, Newton e Page Modificada, os parâmetros da secagem aumentaram de acordo com a temperatura. Sousa et al. (2006), estudando a cinética de secagem do farelo de mamona, constataram o aumento no parâmetro ' $k$ ' do modelo de Page com o aumento da temperatura. 
Tabela 2 - Valores estimados dos parâmetros para os modelos matemáticos avaliados

\begin{tabular}{|c|c|c|c|c|c|c|}
\hline \multirow{2}{*}{ Modelo Matemático } & \multirow{2}{*}{ Temp. $\left({ }^{\circ} \mathrm{C}\right)$} & \multicolumn{5}{|c|}{ Parâmetros } \\
\hline & & a & b & $q$ & $k$ & $n$ \\
\hline \multirow{3}{*}{ Aproximação da Difusão } & 30 & 0,658698 & 0,268608 & - & 0,066328 & - \\
\hline & 40 & 0,741514 & 0,221111 & - & 0,103174 & - \\
\hline & 50 & 0,859117 & 0,250523 & - & 0,089385 & - \\
\hline \multirow{3}{*}{ Exponencial Dois Termos } & 30 & 0,274561 & - & - & 0,109995 & - \\
\hline & 40 & 0,273601 & - & - & 0,180377 & - \\
\hline & 50 & 0,402046 & - & - & 0,128897 & - \\
\hline \multirow{3}{*}{ Henderson e Pabis } & 30 & 0,939804 & - & - & 0,037158 & - \\
\hline & 40 & 0,943046 & - & - & 0,060590 & - \\
\hline & 50 & 0,981976 & - & - & 0,070001 & - \\
\hline \multirow{3}{*}{ Dois Termos } & 30 & 0,678197 & 0,310233 & 0,016906 & 0,062526 & - \\
\hline & 40 & 0,246326 & 0,745824 & 0,100367 & 0,022119 & - \\
\hline & 50 & 0,146342 & 0,859232 & 0,090529 & 0,022813 & - \\
\hline \multirow{3}{*}{ Midilli } & 30 & 1,006133 & 0,000036 & - & 0,079504 & 0,799078 \\
\hline & 40 & 1,004768 & 0,000048 & - & 0,134767 & 0,755227 \\
\hline & 50 & 1,008266 & 0,000034 & - & 0,103781 & 0,872067 \\
\hline \multirow{3}{*}{ Newton } & 30 & - & - & - & 0,039898 & - \\
\hline & 40 & - & - & - & 0,064701 & - \\
\hline & 50 & - & - & - & 0,071343 & - \\
\hline \multirow{3}{*}{ Page } & 30 & - & - & - & 0,080282 & 0,792593 \\
\hline & 40 & - & - & - & 0,137303 & 0,745479 \\
\hline & 50 & - & - & - & 0,102845 & 0,871224 \\
\hline \multirow{3}{*}{ Page Modificada } & 30 & - & - & - & 0,037158 & 0,939804 \\
\hline & 40 & - & - & - & 0,060590 & 0,943046 \\
\hline & 50 & - & - & - & 0,070001 & 0,981976 \\
\hline
\end{tabular}

Fonte: Dados da pesquisa.

\section{Conclusão}

O tempo de secagem do arroz-vermelho decresceu com o aumento da temperatura do ar. Os oito modelos matemáticos ajustados representaram satisfatoriamente o processo de secagem, com coeficientes de determinação superiores a 0,98 e valores de DQM inferiores a 1,0. Entre os modelos matemáticos ajustados aos dados experimentais da cinética de secagem de grãos de arroz-vermelho, os modelos de Aproximação da Difusão e Dois Termos apresentaram os maiores coeficientes de determinação $\left(\mathrm{R}^{2}\right)$ e menores desvios quadráticos médios (DQM).

\section{Referências}

AFONSO JÚNIOR, P. C.; CORRÊA, P. C. Comparação de modelos matemáticos para descrição da cinética de secagem em camada fina de sementes de feijão. Revista Brasileira de Engenharia Agrícola e Ambiental, v. 3, n. 3, p. 349-353, 1999. CORRÊA, P. C.; MACHADO, P. F.; ANDRADE, E. T. Cinética de secagem e qualidade de grãos de milho-pipoca. Ciência e Agrotecnologia, v. 25, n. 1, p. 134-142, 2001.

CORRÊA, P. C. et al. Modelagem matemática para a descrição do processo de secagem do feijão (Phaseolus vulgaris L.) em camadas delgadas. Engenharia Agrícola, v. 27, n. 2, p. 501-510, 2007. doi:10.1590/ S0100-69162007000300020. 
CHRISTENSEN, C. M.; KAUFMANN, H. H. Microflora. In: CHRISTENSEN, C. M. Storage of cereal grain and their products. St. Paul, MN: American Association of Cereals Chemists, 1974. p. 158-192.

KWON, S. L.; SMITH JUNIOR, R. J.; TALBERT, R. E. Comparative growth and development of red rice (Oryza sativa) and rice (O. sativa). Weed Technology, v. 40, n. 1, p. 57-62, 1992.

FURTADO, G. F. et al. Secagem de polpa de seriguela pelo método de camada de espuma. Revista Brasileira de Produtos Agroindustriais, v. 12, n. 1, p. 9-14, 2010.

GOYALDE, N. A. et al. Mathematical modeling of the drying kinetics of sugarcane slices. Revista Brasileira de Produtos Agroindustriais, v. 11, n. 2, p. 117-121, 2009.

LEITE, J. C. A. et al. Simulação de secagem de milho (Zea mays L.) utilizando o modelo matemático de Thompson. Revista de Biologia e Ciências da Terra, v. 5, n. 2, p. 1425, 2005.

LIMA, E. E.; FIGUEIRÊDO, R. M. F.; QUEIROZ, A. J. M. Cinética de secagem de polpa de facheiro. Revista Brasileira de Produtos Agroindustriais, v. 9, n. 1, p. 17-28, 2007.

MADAMBA, P. S.; DRISCOLL, R. H.; BUCKLE, K. A. The thin-layer drying characteristics of garlic slices. Journal of Food Engineering, v. 29, n. 1, p. 75-97, 1996. doi:10.1016/0260-8774(95)00062-3.

MARTINAZZO, A. P. et al. Análise e descrição matemática da cinética de secagem de folhas de capim-limão. Revista Brasileira de Engenharia Agrícola e Ambiental, v. 11, n. 3, p. 301-306, 2007. doi:10.1590/ S1415-43662007000300009.

PEREIRA, J. A.; RAMOS, S. R. R. Cultura do arroz-vermelho (Oryza sativa L.) no Brasil. Teresina: Embrapa Meio-Norte, 2004. (Folder).
RESENDE, O. et al. Modelagem matemática para a secagem de clones de café (Coffea canephora Pierre) em terreiro de concreto. Acta Scientiarum Agronomy, v. 31, n. 2, p. 189-196, 2009. doi:10.4025/actasciagron.v31i2.588.

RESENDE, O.; FERREIRA, L. U.; ALMEIDA, D. P. Modelagem matemática para descrição da cinética de secagem do feijão adzuki (Vigna angularis). Revista Brasileira de Produtos Agroindustriais, v. 12, n. 2, p. 171-178, 2010.

RESENDE, O. et al. Cinética da secagem de clones de café (Coffea canephora Pierre) em terreiro de chão batido. Acta Amazônica, v. 40, n. 2, p. 247-256, 2010. doi:10.1590/S0044-59672010000200002.

SILVA, A. S. et al. Desidratação da polpa de tamarindo pelo método de camada de espuma. Ciência e Agrotecnologia, v. 32, n. 6, p. 1899-1905, 2008. doi:10.1590/S1413-70542008000600032.

SILVA, A. S. et al. Cinética de secagem em camada fina da banana-maçã em secador de leito fixo. Revista Brasileira de Produtos Agroindustriais, v. 11, n. 2, p. 129-136, 2009.

SOGI, D. S. et al. Water sorption isotherm and drying characteristics of tomato seeds. Biosystems Engineering, v. 84, n. 3, p. 297-301, 2003. doi:10.1016/ S1537-5110(02)00275-1.

SOUSA, M. B. et al. Cinética de secagem do farelo de mamona. Revista Brasileira de Produtos Agroindustriais, v. 8, n. 2, p. 135-146, 2006.
Recebido: 27/05/2011

Received: 05/27/2011

Aprovado: $18 / 07 / 2013$

Approved: 07/18/2013 